\title{
Book review: David Bronstein, Aristotle on Knowledge and Learning: The Posterior Analytics. Oxford: Oxford University Press, 2016. (pp.xiii-272).
}

\author{
University of Campinas \\ Department of Philosopby \\ Campinas, SP \\ Brazil \\ baz1289@gmail.com
}

Breno Andrade Zuppolini

Article info

CDD: 185

Received: 17.10.2017; Accepted: 17.10.2017

DOI: http://dx.doi.org/10.1590/0100-6045.2017.V40N4.BZ

Keywords:

Aristotle

Learning

Knowledge

\section{ABSTRACT}

This is a review of David Bronstein's book "Aristotle on Knowledge and Learning: The Posterior Analytics" (Oxford: Oxford University Press, 2016)

David Bronstein's outstanding book is one of the greatest contributions to the study of Aristotle's Posterior Analytics (hereafter, APo) of the last years. All of his claims are carefully argued in admirably clear prose. The book is original in many ways, but its main achievement is an illuminating reconstruction of Aristotle's account of learning. Bronstein argues that we can get a better understanding of this account if we frame it as a reaction to Meno's Paradox (Meno 80e 1-5). According to the Paradox, for any $x$, either we know $x$ or we do not know it. In either case, we cannot search for $x$ : if we do not know $x$, we cannot even identify the object of our investigation; if we already know $x$, investigating it is pointless. The fact that the APo contain only one explicit reference to this puzzle ( $A P_{0} \mathrm{I} 1,7^{\text {a }}$ 29-30) is irrelevant. Bronstein convincingly argues that Aristotle is in many passages offering solutions for (and sometimes explicitly formulating) what can be taken as different versions of the Paradox. The result is a systematic discussion of three different kinds of learning (listed in

Manuscrito - Rev. Int. Fil. Campinas, v. 40, n. 4, pp. 179-186, out.-dez. 2017. 
Metaph. A 9, 992 b 30-33): "learning by demonstration" is analysed in Part I, "learning by definition" in Part II, and "learning by induction" in Part III.

One of the main theses of the book is that inquiry, for Aristotle, follows a "Socratic Picture" (as Bronstein calls it), which can be divided into five stages:

Stage 1: We do not know whether a subject $\mathrm{S}$ exists and we seek whether it exists.

Stage 2: We know that $\mathrm{S}$ exists, and we seek what it is (its essence).

Stage 3: We know what $S$ is, and we seek whether a predicate $P$ belongs to it as one of its demonstrable attributes.

Stage 4: We know that $\mathrm{P}$ belongs to $\mathrm{S}$ as one of its demonstrable attributes and we seek why it belongs.

Stage 5: We know why P belongs to S.

This five-stage picture shows us that learning is not an "all-or-nothing" matter, providing therefore a way-out to Meno's dilemma. First, we learn by induction preliminary accounts specifying the meaning of conceptual terms (also known as "nominal definitions"), so we can investigate whether or not they denote existing kinds (APo II 19 and Bronstein's Chapter 13). We move from Stage 1 to Stage 2, for instance, when we know that there is a real kind satisfying our account of a given subject-term "S". Second, we get from Stage 2 to Stage 3 by division or induction: if $\mathrm{S}$ is what Bronstein calls a "subordinate subject-kind" (a species of a genus, e.g. human being), its essence is discovered by division; if $\mathrm{S}$ is a "primary subject-kind" (a genus, e.g. animal), its essence is grasped by induction (APo II 13 and Bronstein's Chapter 12). Once we know the essence of our subject $\mathrm{S}$, we start investigating its demonstrable attributes. For Aristotle, knowing that a predicate $\mathrm{P}$ belongs to $\mathrm{S}$ is the same as knowing that $\mathrm{P}$ exists, so the passage from Stage 3 to Stage 4 also involves using a preliminary account to determine whether "P" corresponds to an existing kind (now, a "predicative" or non-substantial one). Finally, we move from Stage 4 to Stage 5 by grasping the cause of $\mathrm{S}$ being $\mathrm{P}$, which for Aristotle is the same as discovering the essence of $\mathrm{P}$ (APo II 8 and Bronstein's Chapter 10). As the inquirer moves from one stage to the other, she upgrades her epistemic status by engaging in the three types of learning. Before undertaking a proper "scientific" investigation, she learns preliminary accounts "by induction". When she is on her way to become a 
scientist, she learns "by definition" the essence of attributes (by using demonstration) and subject-kinds (by using division or induction). Finally, once the inquirer becomes an expert scientist, she learns "by demonstration" by getting a better understanding of the explanatory power of previously obtained definitions (see p. 7 and p. 73).

Bronstein also offers a promising - although "admittedly speculative" (p. 49) - solution to a classic exegetical problem, recently revived in the literature by Michael Ferejohn (2013, 147 ff.). As we have seen, the Socratic account of inquiry Bronstein attributes to Aristotle involves the essence of subjects as well as the essence of predicates. In fact, Aristotle seems to endorse two different (and possibly incompatible) models of scientific explanation. According to what Bronstein calls "Model 1", the cause of a subject S being P is the essence of S. A "Model 2" demonstration, on the other hand, is such that the cause of S being P is the essence (or the causal part of the essence) of P. Bronstein argues that Model 1 and Model 2 demonstrations are connected in the following way (pp. 48-50). We know, by demonstration, that the moon (minor term) is eclipsed (major term) because of the screening of the sun by the earth (middle term). Since the eclipse is defined as loss of light from the moon because of screening of the sun by the earth (APo II 2, 90a 14-18), we can say that the major (eclipse) and the middle term (screening of the sun by the earth) are definitionally, and therefore "immediately", connected (see 93a 36). However, the connection between the middle (screening of the sun by the earth) and the minor term (moon) requires further explanation. This explanation probably involves a reference to essential features of the moon, like its natural movement and its position in the composition of celestial spheres. Thus, although the demonstration of the eclipse follows Model 2, once we pursue a demonstration of its minor premise we might end up with an explanation following Model 1. This solution is attractive for many reasons. First, it explains how the two models endorsed by Aristotle can be taken as parts of the same coherent doctrine. Second, it guarantees a prominent place to Model 2 demonstrations, which are often neglected or wrongly taken (to my eyes at least) to be secondary, less important types of explanations - other exceptions to this tendency include Goldin (1996), Charles (2000), and Angioni (2016). Thirdly, Bronstein's account of these two models makes Aristotle's theory philosophically interesting in a particular way: the reason why there is a regular, stable relation between a demonstrable attribute and its subject is that their essences are linked by a chain of causal connections. 
Let me now discuss some unsolved problems in Bronstein's book. We can distinguish two schools of interpretation, so to speak, when it comes to the relation between demonstrative knowledge (the knowledge a scientist has of demonstrable truths) and nous (the knowledge a scientist has of indemonstrable principles, mainly definitions). According to one of these schools (often referred to as "intuitionist" or "rationalist"), the principles become known in advance of any demonstrative practise and are grasped independently of their explanatory connections to other truths in the domain (see, for instance, Irwin 1988; Ferejohn 1991; 2009). The other school (sometimes called "interrelational" or "explanationist") argues that having noetic knowledge of the principles, including definitions, involves grasping them as principles, i.e. as premises from which other truths are demonstrated, but which are not demonstrated from more basic premises (Kosman 1973; Burnyeat 1981; McKirahan 1992; Charles 2000). Bronstein seems to be somewhere between the two schools. On the one hand, his Socratic Picture contradicts the "explanationist" approach, since we get to know the essence of a subject $\mathrm{S}$ before we start investigating the cause of $\mathrm{S}$ being $\mathrm{P}$ (Stage 3 precedes Stage 4). On the other hand, he also disagrees with "rationalist" interpretations, since, for him, having nous of the essence of $\mathrm{S}$ requires knowing this essence as the cause of $\mathrm{S}$ being $\mathrm{P}$ (p. 9; p. 73; p. 222).

The only way Bronstein can keep this intermediate position is by distinguishing non-noetic from noetic knowledge of essences, the first depending only on division and/or induction, the second requiring some demonstrative practice. For the "explanationist" interpretation, a non-noetic grasp of the essence of (e.g.) human being is the knowledge of the fact that human beings are two-footed tame animals (supposing that this is the essence of human beings). This merely factual knowledge differs from the (noetic) knowledge that being a two-footed tame animal is the essence of human beings, which involves grasping it as the cause of their demonstrable attributes. In Bronstein's view, on the other hand, the method of division can give us knowledge not only of the fact that human beings are two-footed tame animals, but knowledge that this is the essence of human beings. He correctly points out that in APo II 13 Aristotle claims that division gets us to the definition of the object (97b 12-13). However, the philosopher never affirms or implies that division gives us the knowledge of the essence as an essence. For several reasons, the claim that we can know an essence as such independently of its status as a cause is anti-Aristotelian in spirit. The philosopher states that the way we distinguish indemonstrable premises (including definitions) from demonstrable ones is by organizing a whole body of 
truths based on their causal connections $\left(A \operatorname{Pr} \mathrm{I} 30,46^{\mathrm{a}} 17-27\right)$. His own scientific practice goes in the same direction. Treatises such as the Historia Animalium, which (one might say) presents a collection of facts grasped by division and induction, do not distinguish causally fundamental truths from demonstrable truths. This is a task Aristotle undertakes only in explanatory studies such as de Partibus Animalium or de Generatione Animalium. The fact that, for Aristotle, grasping an essence as such involves grasping it as a cause or explanatory factor is not exactly surprising. After all, essences are essentially causes of a certain kind (namely, formal causes). If division somehow allows us to distinguish essential from demonstrable attributes, the criteria are unclear, and the proponents of the "rationalist" interpretation may argue that some sort of "intuition" or "mental vision" (nous, according to them) must be part of the process. If, on the other hand, division itself involves explanatory concerns, the members of the "explanationist" school may think their case is already won.

A different but related difficulty concerns the essence of attributes, which, according to Bronstein, are not discovered by division or induction like the essence of subject-kinds. We get to know the essence of the lunar eclipse, for instance, by identifying the cause of the moon being eclipsed (or suffering a certain loss of light). Once this cause is identified, the eclipse can be defined as a loss of light from the moon caused by screening of the sun by the earth. Here, the reader might expect Bronstein to claim that "learning by definition" and "learning by demonstration" coincide, since he accepts that demonstration is the method for learning definitions of attributes. However, he insists that even here the two kinds of learning are distinct. "Learning by definition" is a process in which the inquirer (not the expert) engages, and consists in discovering essences previously unknown. On the other hand, only the expert can "learn by demonstration", since she is able to acquire "a new understanding of the explanatory power of a definition she already knows" (p. 72). While learning by demonstration "proceeds from definitions", learning by definition "proceeds to them" (p. 73). I must confess I fail to understand the distinction Bronstein is willing to draw. For him, learning by demonstration consists in grasping explanatory connections between previously recognized facts: knowing $x$ and $y$ in advance ( $x$ being the cause of $y$ ), the scientist realizes that $x$ is the cause of $y$ (pp. 39-40). However, a demonstration reveals the essence of (e.g.) the lunar eclipse precisely because it displays a causal connection between screening of the sun by the earth and the loss of light from the moon. It is unclear what kind of new information the expert can obtain by formulating (again?) a demonstration that has already revealed to him the cause 
and essence of eclipse. Still, Bronstein's efforts to make this distinction are understandable. He is one of the few interpreters (if not the only one) that takes Aristotle's use of the phrase "learning by demonstration" (APo I 18, 81 a 39-40; Metaph. A 9, 992 30-33) seriously and tries to explain it without reducing demonstration to a pedagogic procedure (as Barnes 1969, for instance, does). In fact, this is one of the most significant contributions of his book.

I would like to address a final issue. As we have seen, Bronstein claims that the essence of subject-kinds is grasped by division and induction, while the essence of attributes (and processes) is grasped by demonstration. The reason, according to him, is that the essences of attributes are "causally complex" and have the structure "A holds of C because of B". In virtue of this causally complex structure, each of the elements in the essence of an attribute corresponds to one of the three terms involved in a syllogistic demonstration (Bronstein's Chapter 7 and 10). On the other hand, the essences of subjects are "causally simple", consisting in a combination of genus plus differentiae (Bronstein's Chapter 12), which explains why they are grasped not by demonstration, but by division and/or induction. The relevant text here is $A P_{0}$ II 9, where Aristotle affirms that only things "whose cause is something different" have definitions isomorphic to demonstrations (93b 25-28). Attributes and processes such as eclipse and thunder would somehow be "different" from their cause, which would make their essence "causally complex". Subject-kinds (substantial beings, in particular) would be in a way "the same" as their causes, and hence their essences would be "causally simple" (Bronstein's Chapter 9). I am not convinced that APo II 9 draws a distinction between attributes and subject-kinds (or between non-substantial and substantial beings). As a matter of fact, in Metaph. VII 17 and VIII 2-4, Aristotle applies to substances the theory of definition developed in APo II 8 (see Charles 2000; Peramatzis 2011; 2013). One may argue, as Bronstein does (p. 101), that the idea that sensible substances are analysable as compounds of form and matter (crucial to the arguments in the Metaphysics) is absent in the APo. However, Aristotle's own examples in $A P_{0}$ II 8, 93a 22-24, include substances (human being and soul), which suggests that the interdependence between defining and explaining holds good for subject-kinds as well. It is true that these examples are not fully explored, as thunder and eclipse are. Nevertheless, Aristotle might have thought that bringing hylomorphism to the (already complicated) discussion in $A P o$ II 8 would create extra difficulties unnecessarily. The absence of hylomorphic considerations in the $A P o$ is not a strong reason to think that Aristotle did not have consolidated views about the issue by the time the treatise 
was written - in $A P_{0}$ II 11, for instance, he explores his theory of four causes, one the best-known doctrines of his philosophy of nature. Actually, in APo II 9, the entities whose essence is "not something different" seem to be conceptually simple items, rather than substances (Aristotle's example is "unit"). Still, there is a sense in which defining and explaining remain interdependent activities even in the case of these simple entities. In a famous a passage from De Anima I 1, Aristotle claims that a definiens that does not help us understand the derivative properties of the definiendum is not properly scientific, but "dialectical and empty" $\left(402^{\mathrm{b}} 16-403^{\mathrm{a}} 2\right.$ ). In other words, knowing the essence of $\mathrm{X}$ as the essence of $\mathrm{X}$ involves understanding how it explains X's demonstrable attributes, even if there is not a demonstration isomorphic to the essence of $\mathrm{X}$.

If this review focused on what I take to be difficulties for Bronstein's interpretation, it is for a very simple reason: the merits of his book speak for themselves. As with any great philosophical work, even when the readers disagree with the views he advances, they will end up with a better understanding of their own ideas about the topics discussed. For anyone interested in Aristotle's theory of knowledge, reading and reacting to this book is indispensable.

\section{References}

ANGIONI, L. "Aristotle's definition of scientific knowledge (APo71b9-12)". Logical Analysis and History of Philosophy 19: 79-105, 2016.

BARNES, J. “The Aristotle's Theory of demonstration”. Phronesis 14 (2): 123-152, 1969.

Burnyeat, M. “Aristotle on Understanding Knowledge”. In: Berti, E. Aristotle on Science: The Posterior Analytics, Proceedings of the Eighth Symposium Aristotelicum (pp. 97-139). Padova: Editrice Antenore, 1981.

Charles, D. Aristotle on Meaning and Essence. Oxford: Clarendon Press, 2000.

FEREJOHN, M. The origins of Aristotelian science. New Haven: Yale University Press, 1991.

"Empiricism and First Principles in Aristotle". In: Anagnostopoulos, G. (ed.) A Companion to Aristotle (pp. 66-80). Chichester: Wiley-Blackwell, 2009.

Manuscrito - Rev. Int. Fil. Campinas, v. 40, n. 4, pp. 179-186, out.-dez. 2017. 
Formal Causes: Definition, Explanation, and Primacy in Socratic and Aristotelian Thought. Oxford: Oxford University Press, 2013.

Goldin, O. Explaining an Eclipse: Aristotle's Posterior Analytics 2.1-10. Ann Arbor: University of Michigan Press, 1996.

IRWIN, T. Aristotle's First Principles. Oxford: The Clarendon Press, 1988.

Kosman, L. "Understanding, Explanation, and Insight in the Posterior Analytics". In: Lee, E.N. Mourelatos, A.P.D. \& Rorty, R.M. (eds.) Exegesis and Argument, Studies in Greek Philosophy presented to Gregory Vlastos. New York: Humanities Press, 1973.

MCKIRAhan, R. Principles and Proofs. Princeton: Princeton University Press, 1992.

Peramatzis, M. Priority in Aristotle's Metaphysics. Oxford: Oxford University Press, 2011.

"Science and Metaphysics in Aristotle's philosophy." Metascience 22 (2): 303-315, 2013. 